\title{
A realização variável da segunda pessoa por bilíngues em vêneto e português em uma comunidade rural do Espírito Santo
}

DOI: http://dx.doi.org/10.21165/el.v48i2.2357

\section{Edenize Ponzo Peres ${ }^{1}$ \\ Maria do Socorro Vieira Coelho²}

\section{Resumo}

Este trabalho objetiva analisar as consequências do contato linguístico que ocorreu em uma comunidade do interior do Espírito Santo, colonizada por imigrantes provenientes do Vêneto, Itália, que ali chegaram no final do século XIX. Especificamente, investigamos o uso da $2^{a}$ pessoa do português por parte de quatro bilíngues em vêneto e português, netos desses imigrantes, sendo dois homens e duas mulheres, com idade acima de 57 anos e com baixa escolarização. Os dados foram coletados por meio de entrevistas sociolinguísticas, sendo analisadas cinco variáveis linguísticas e uma extralinguística. Os resultados apontam o emprego de você(s), de cê(s) e de ocê(s) pelos informantes. Nossos resultados não se alinham aos obtidos em outras comunidades brasileiras, evidenciando que, em situações de contato linguístico, a língua materna exerce influência variável na segunda língua, a depender dos fatores linguísticos e sociais envolvidos.

Palavras-chave: sociolinguística; contatos linguísticos; pronomes de segunda pessoa; vêneto; português.

1 Universidade Federal do Espírito Santo (UFES), Vitória, Espírito Santo, Brasil; eponzoperes@gmail.com; https://orcid.org/0000-0002-8552-5732

2 Universidade Estadual de Montes Claros (UNIMONTES), Montes Claros, Minas Gerais, Brasil; soccoelho@hotmail.com; https://orcid.org/0000-0002-3732-467X 


\title{
The variable realization of the second person by bilinguals in Veneto and Portuguese in a rural community of Espírito Santo
}

\begin{abstract}
This work aims to analyze the consequences of the linguistic contact that occurred in a community of the interior of the state of Espírito Santo, colonized by immigrants from Veneto, Italy, who arrived there in the late 19th century. Specifically, we investigate the use of the second-person pronouns of Portuguese, by four bilinguals in Venetian and Portuguese, grandchildren of these immigrants, two men and two women, aged over 57 years old and with low schooling. Data were collected through sociolinguistic interviews, with five linguistic variables being analyzed and one extralinguistic. The results point to the employment of você(s), cê(s) and ocê(s) by the informants. Our results are not in line with other Brazilian communities, evidencing that in situations of language contact the mother tongue has a variable influence in the second language, depending on the linguistic and social factors that are involved.
\end{abstract}

Keywords: sociolinguistics; language contact; second-person pronouns; Venetian; Portuguese.

\section{Introdução}

Quando duas línguas entram em contato, geralmente ocorrem mudanças em uma das línguas e, algumas vezes, em ambas (BAKER; JONES, 1998; MATRAS, 2009). Nesses casos, normalmente, a língua minoritária - como as de imigração - sofre mais influência da língua majoritária - a do país de acolhimento - do que o oposto, devido ao maior status desta (APPEL; MUYSKEN, 1996; MYERS-SCOTTON, 2006), e essa influência se dá em todos os níveis - fonológico, lexical, sintático, semântico e pragmático (WEINREICH, 1970 [1953]; MONTRUL, 2013). Também de modo geral, no contato, os possíveis empréstimos acontecem mais com as palavras gramaticais - adjetivos, substantivos, verbos - do que com as palavras funcionais, como os artigos, pronomes e conjunções, pois os elementos gramaticais têm uma relação direta com os conteúdos culturais, sendo mais fácil a sua inserção no léxico da outra língua (APPEL; MUYSKEN, 1996; MATRAS, 2009).

Por sua vez, o contato que ocorreu entre a língua vêneta e o português em São Bento de Urânia, um distrito rural do município de Alfredo Chaves, Espírito Santo, fez com que a língua de herança fosse substituída pelo português, embora os traços do vêneto estejam presentes na linguagem dos moradores da comunidade, mesmo entre as crianças, principalmente no nível fonético-fonológico (PETERLE, 2017). Quanto aos demais níveis, os traços vênetos são menos visíveis, mas eles existem. Outra asserção dos estudos de contatos linguísticos é a de que a história e a estrutura social da comunidade estão intrinsecamente relacionadas às consequências desse contato. Assim, a linguagem dos 
habitantes de São Bento de Urânia apresenta tanto características vênetas quanto do português falado em zonas rurais, pelo contato com tropeiros e meeiros oriundos de outras localidades do Espírito Santo e de Minas Gerais (DADALTO, 2017).

Com base nesses pressupostos, temos por objetivo geral analisar o uso variável da segunda pessoa por quatro descendentes de imigrantes italianos, bilíngues em vêneto e português, todos acima de 57 anos e com pouca escolarização, nascidos e residentes no distrito de São Bento de Urânia, buscando: a) conhecer os contextos condicionadores do uso da segunda pessoa; e b) comparar nossos resultados com os de pesquisas realizadas em comunidades do Espírito Santo e de Minas Gerais, rurais e urbanas, em que (não) houve imigração, a fim de aprofundarmos nossos conhecimentos a respeito das consequências dos contatos entre línguas. Cremos que as comunidades colonizadas por imigrantes do Espírito Santo podem contribuir com esses estudos, e São Bento de Urânia é privilegiada quanto a esse aspecto, pois é uma das que mais preservam a sua língua de herança. Por isso, ela servirá de parâmetro de comparação para estudos em outras localidades do estado.

Para expormos os nossos resultados, dividimos este trabalho em seis seções, além desta Introdução. Na segunda, apresentamos um breve histórico da colonização estrangeira no Espírito Santo, a fim de que se compreendam as condições em que ocorreram os contatos linguísticos no estado. Na terceira, tratamos do fenômeno analisado. Na quarta, apresentamos os autores e os procedimentos metodológicos que seguimos para dar suporte às nossas análises. Na quinta, analisamos os nossos dados, à luz da teoria Sociolinguística Variacionista e do Contato Linguístico. Na sexta, tecemos nossas considerações finais e, por fim, aparecem listadas as nossas referências.

\section{Breve histórico dos contatos linguísticos no Espírito Santo}

Para falarmos sobre os contatos linguísticos que ocorreram no Espírito Santo, é necessário remetermo-nos, mesmo que brevemente ${ }^{3}$, à história do povoamento do estado. Servindo de proteção natural contra os ladrões de ouro das minas localizadas a oeste da então província, não havia interesse do governo imperial em colonizá-lo, ficando a escassa população ${ }^{4}$ concentrada em poucos pontos do litoral ou próximos a ele (MOREIRA; PERRONE, 2007; SALETTO, 2011).

Por essa razão, o interior não tinha qualquer infraestrutura, estando coberto por mata virgem. Porém, com o declínio da extração do ouro em Minas Gerais, não havia mais

3 Para maiores informações sobre a história do Espírito Santo, vejam-se as obras constantes do sítio do Arquivo Público do Estado do Espírito Santo: https://ape.es.gov.br.

4 Entretanto, é certo que no interior habitavam os indígenas, especialmente nas regiões mais baixas e com temperaturas menos frias. 
razão para a obstrução do desenvolvimento do Espírito Santo e, dessa forma, em meados do século XIX, foram abertas as oportunidades para a sua ocupação, e a solução mais rápida encontrada pelo Império e pela Província foi atrair imigrantes (OLIVEIRA, 2008).

No século XIX, vieram para o Espírito Santo 47.026 imigrantes, sobretudo europeus (FRANCESCHETTO, 2014), o que correspondia a 22,42\% da população capixaba, que, em 1900 , era de 209.783 pessoas $^{5}$. Do total de imigrantes, $36.666^{6}(67,71 \%)$ eram italianos, provenientes principalmente do Vêneto, região norte da Itália. A eles foram destinados lotes localizados na região centro-serrana da então província, afastados dos demais núcleos populacionais?

Esses imigrantes enfrentaram grandes dificuldades para se instalarem em suas terras, devido, entre outras razões, à falta de assistência dos governos brasileiro e capixaba; ao isolamento a que foram submetidos e ao desconhecimento da fauna e da flora nacionais (DERENZI, 1974). Entretanto, vencidos os primeiros desafios da ocupação da terra, os imigrantes progrediram e hoje seus descendentes estão em grande parte do território do Espírito Santo, ocupando postos de destaque na sociedade capixaba.

A forma de povoamento do estado favoreceu, nos primeiros anos, o uso das línguas de herança por parte dos imigrantes. Porém, com o passar dos anos, os contatos com os falantes de português se intensificaram, fazendo com que aquelas línguas fossem gradativamente sendo substituídas pela língua oficial do país. Atualmente, com exceção do hunsrückisch (KLIPPEL-MACHADO, 2018) e principalmente do pomerano (BREMENKAMP, 2014), as línguas faladas pelos imigrantes italianos sobrevivem nas zonas rurais, entre os mais idosos (PERES, 2014; PERES, DADALTO; BOTTER, 2016). São Bento de Urânia é uma dessas comunidades.

5 Fonte: IBGE: www.censo2010.ibge.gov.br/sinopse/index. php?dados $=4 \& u f=00$. Acesso em: 30 mar. 2014.

6 Fonte: https://ape.es.gov.br. Acesso em: 05 nov. 2018.

7 Em Martinuzzo (2009), é possível visualizar um mapa com as etapas do povoamento do Espírito Santo. Disponível em: http://www.institutosincades.org/painel/arquivos/ downloads/122122260911livro_germanicos.pdf. Acesso em: 05 nov. 2018. 


\section{O fenômeno analisado - as formas você, ocê e cề}

O pronome você originou-se da forma de tratamento Vossa Mercê. Essa expressão surgiu no século XIV, firmando-se no século $X V$, sendo usada inicialmente para 0 tratamento ao rei. As formas "Vossa + Nome", como Mercê, ao exaltar as qualidades morais e a superioridade do monarca, acabaram por substituir o pronome vós, utilizado indistintamente tanto para o rei quanto para outros nobres. Entretanto, já na segunda metade do século XV, a expressão Vossa Mercê para tratamento ao rei foi substituída por outras formas nominais, como Senhoria, Alteza e Majestade, ao mesmo tempo em que Vossa Mercê se ia vulgarizando, chegando, por fim, a ser usada para qualquer pessoa não íntima, a quem se deveria respeito.

Em consequência da vulgarização de seu uso, essa expressão, um tanto longa, sofreu consecutivas reduções fonéticas, dando origem a diversas variantes e, entre elas, a forma você. No início do século XVI, era essa a situação da língua portuguesa, a qual foi trazida para o Brasil. Durante o processo de gramaticalização pelo qual Vossa Mercê passou, originando o pronome você, as duas formas percorreram caminhos distintos, na língua: enquanto Vossa Mercê tinha mobilidade na frase, você era usado apenas na função de sujeito pré-verbal, expandindo-se lentamente para outros contextos sintáticos.

Outra consequência do mesmo processo é a reorganização do quadro pronominal da língua, com a entrada de uma forma que fazia referência à segunda pessoa, mas fazendo a concordância verbal com a terceira. Essa situação, por sua vez, originou a necessidade de preenchimento do sujeito, o que fez aumentar a frequência de uso desse pronome, gerando novas reduções e dando origem a outras formas, usadas atualmente no português brasileiro (PB), como ocê e cê.

Coelho (2008) apresenta as variantes da expressão Vossa Mercê no PB, atestadas por diversos autores: cê, mecê, mincê, ocê, oncê, sucê, suncê, ucê, vacê, vancê, vasmincê, vassuncê, você, vomincê, voncê, vormincê, vos'mecê, vosmincê, vossamecê, vossecê, vossemecê e vossuncê.

As formas você, ocê e cê já foram objeto de diversas pesquisas, em algumas localidades do Brasil. Esses estudos apontam uma importante contribuição para a descrição

8 Neste trabalho, não será possível aprofundarmo-nos nas discussões sobre o surgimento, os aspectos estruturais e sociais das mudanças pelas quais passaram e os usos, em Portugal e no Brasil, da expressão Vossa Mercê e das formas você, ocê e cê. Para informações mais detalhadas a respeito desses temas, dentro da vasta bibliografia existente, podem ser consultados: Luz (1956), Nascentes (1956), Ali (1965), Cintra (1972), Câmara Jr. (1976), Duarte (1996), Faraco (1996), Vitral (1996), Menon (1995, 2000), Cook (1997), Lopes (2003a, 2003b), Ramos e Oliveira (2002), Oliveira e Ramos (2002), Coelho (2008), Scherre (2015), Lopes, Oliveira e Carvalho (2016) etc. 
das variedades do português, além de subsidiar planejamentos de ensino de língua portuguesa mais adequados às realidades locais. Para o nosso trabalho, particularmente, ao compararmos os nossos resultados com alguns dos obtidos, importa-nos refletir sobre as consequências estruturais e sociais do contato de línguas, principalmente em se tratando de uma pequena comunidade rural, colonizada por imigrantes.

\section{Referencial teórico e procedimentos metodológicos}

Nossas análises foram realizadas tomando por base os pressupostos teóricometodológicos da Sociolinguística (LABOV, 1972; 2001; BORTONI-RICARDO, 2011 etc.), mas, tendo em vista que a comunidade foi colonizada por imigrantes de origem vêneta e que os nossos informantes são bilíngues, também os estudos de contatos linguísticos (WEINREICH, 1970 [1953]; APPEL; MUYSKEN, 1996; BAKER; JONES, 1998; COULMAS, 2005; MYERS-SCOTTON, 2006; MATRAS, 2009; MONTRUL, 2013 etc.) nos serviram de apoio.

A comunidade pesquisada é São Bento, localizada no distrito de Urânia, em Alfredo Chaves, Espírito Santo. Segundo nossos informantes, a comunidade foi formada por oito famílias de imigrantes do Vêneto, Itália, no final do século XIX. O isolamento inicial (VILAÇA, 2010) e o fato de todos os moradores serem provenientes da região do Vêneto, na Itália, indicam que eram variedades do vêneto as utilizadas na comunicação dos locais, inicialmente.

O distrito se localiza a $40 \mathrm{~km}$ de distância da Sede de Alfredo Chaves, ligado por uma estrada de terra sem iluminação que corta a mata virgem. Outra via de acesso é uma estrada que conecta a comunidade à BR 262, asfaltada apenas em 2006. Sua altitude é de cerca de $1.250 \mathrm{~m}$, o que indica temperaturas baixas durante todo o ano, especialmente no inverno. Todo o distrito tem atualmente cerca de 900 pessoas e a comunidade de São Bento, aproximadamente 500 moradores, praticamente todos agricultores.

São Bento conta com uma escola de ensino fundamental, uma igreja católica e uma adventista, um posto de saúde com atendimento médico quinzenal, uma mercearia, uma pastelaria que funciona nos fins de semana e uma lanchonete inaugurada recentemente. Após a celebração dominical, os católicos - que são a maioria - se reúnem no pátio da igreja para conversar e jogar bocha e mora, momentos em que se pode ouvir o vêneto (COMINOTTI, 2015; PETERLE, 2017).

Além dos parentes que vivem fora, a comunidade não recebe muitos visitantes, com exceção das duas festas anuais - da colheita da uva e do inhame -, que atraem turistas de outras localidades. Na comunidade não circulam jornais ou revistas e poucas casas dispõem de internet, mas existe torre de telefonia celular, inaugurada em dezembro de 2014. 
Nossos informantes são quatro descendentes de imigrantes italianos, nascidos e residentes na comunidade e bilíngues com diferentes graus de proficiência em vêneto. As características dos entrevistados aparecem a seguir.

a). SL: Nascido em 1936 (78 anos, à época da entrevista), sexo masculino, agricultor, com menos de um ano de escolarização, falante de vêneto. A família $L$ é procedente da província de Treviso, Vêneto.

b). RB: Nascido em 1941 (73 anos), sexo masculino, agricultor, sem escolarização formal, falante de vêneto. A família B é procedente da província de Pádova, Vêneto.

c). CDB: Nascida em 1946 (68 anos), sexo feminino, com menos de um ano de escolarização, afirma que apenas compreende o vêneto. O Arquivo Público do Estado do Espírito Santo não tem dados a respeito da procedência da família D, e a informante somente sabe que seus antepassados são vênetos.

d). JG: Nascida em 1956 (58 anos), sexo feminino, com quatro anos de escolarização, afirma que somente compreende o vêneto. A família $\mathrm{G}$ é procedente da província de Treviso, Vêneto.

Os dados foram coletados em julho de 2014, na casa dos informantes ou no pátio da igreja, por meio de entrevistas sociolinguísticas realizadas por uma das autoras deste trabalho e por uma ex-professora e frequentadora assídua da comunidade. Após as conversas, os Termos de Consentimento Livre e Esclarecido (TCLE) ${ }^{9}$ foram lidos para os informantes, que os assinaram, dando-nos autorização para fazer uso das informações prestadas. Para procedermos a este estudo, as gravações foram ouvidas buscando-se a pronúncia fiel dos informantes quanto às formas de segunda pessoa: você(s), ocê(s) e cê(s) ${ }^{10}$. Os grupos de fatores analisados são:

a) Função sintática da forma: sujeito, complemento de verbo sem preposição, complemento de verbo com preposição, complemento de nome;

b) Morfologia da forma verbal: forma simples, locução verbal;

9 Os informantes RB e SL, embora tenham pouca ou nenhuma escolarização formal, sabem assinar seu nome.

10 Nos dados dos quatro informantes pesquisados, encontramos alguns zeros, ou seja, a não ocorrência explícita das formas, mas, por não termos certeza sobre a qual delas o zero fazia referência, optamos por não analisá-lo, seguindo outros estudiosos do tema. 
c) Paradigma flexional do verbo: regular ou irregular;

d) Contexto de interpretação da forma: interpretação definida ou indefınida;

e) Tipo de frase em que a forma ocorre: afirmativa, declarativa ou interrogativa; e

f) Sexo/gênero dos informantes: feminino ou masculino.

O próximo passo foi a análise dos dados, realizada a partir dos resultados gerados pelo Programa Goldvarb X (SANKOFF, TAGLIAMONTE, SMITH, 2005), que foi utilizado para verificarmos quais fatores estariam condicionando o uso de cada variante. Na próxima seção, apresentaremos os resultados obtidos.

\section{Resultados}

O Programa Goldvarb X gerou os seguintes resultados gerais:

Tabela 1. Resultados gerais para o uso da segunda pessoa em São Bento de Urânia

\begin{tabular}{|c|c|c|c|c|c|c|c|c|}
\hline \multirow{2}{*}{\multicolumn{2}{|c|}{$\begin{array}{c}\text { GRUPOS DE FATORES } \\
\text { N }\end{array}$}} & \multicolumn{2}{|c|}{ VOCÊ } & \multicolumn{2}{|c|}{ CÊ } & \multicolumn{2}{|c|}{ OCE } & \multirow{3}{*}{$\begin{array}{c}\text { TOTAL } \\
\begin{array}{c}111 \\
(93,3 \%)\end{array}\end{array}$} \\
\hline & & $\%$ & $\mathrm{~N}$ & $\%$ & $\mathrm{~N}$ & $\%$ & & \\
\hline \multirow{4}{*}{$\begin{array}{l}\text { Função } \\
\text { sintática da } \\
\text { forma }\end{array}$} & Sujeito & 46 & 41,4 & 52 & 46,8 & 13 & 11,7 & \\
\hline & $\begin{array}{c}\text { Compl. Verbo } \\
\text { s/ prep. }\end{array}$ & 3 & 100 & 0 & - & 0 & - & $3(2,5 \%)$ \\
\hline & $\begin{array}{l}\text { Compl. Verbo } \\
\text { c/ prep. }\end{array}$ & 3 & 100 & 0 & - & 0 & - & $3(2,5 \%)$ \\
\hline & Compl. nome & 2 & 66,7 & 0 & - & 1 & 33,3 & $2(1,7 \%)$ \\
\hline \multirow{2}{*}{$\begin{array}{l}\text { Morfologia da } \\
\text { forma verbal }\end{array}$} & $\begin{array}{l}\text { Forma } \\
\text { simples }\end{array}$ & 43 & 45,7 & 43 & 45,7 & 8 & 8,5 & $\begin{array}{c}94 \\
(79,0 \%)\end{array}$ \\
\hline & $\begin{array}{l}\text { Locução } \\
\text { verbal }\end{array}$ & 10 & 40 & 9 & 36 & 6 & 24 & $\begin{array}{c}25 \\
(21 \%)\end{array}$ \\
\hline
\end{tabular}

(continua) 


\begin{tabular}{|c|c|c|c|c|c|c|c|c|}
\hline \multirow{2}{*}{$\begin{array}{l}\text { Paradigma } \\
\text { flexional do } \\
\text { verbo }\end{array}$} & Verbo regular & 23 & 46,9 & 18 & 36,7 & 8 & 16,3 & $\begin{array}{c}49 \\
(41,2 \%)\end{array}$ \\
\hline & $\begin{array}{l}\text { Verbo } \\
\text { irregular }\end{array}$ & 30 & 42,9 & 34 & 48,6 & 6 & 8,6 & $\begin{array}{c}70 \\
(58,8 \%) \\
\end{array}$ \\
\hline \multirow{2}{*}{$\begin{array}{l}\text { Contexto de } \\
\text { interpretação } \\
\text { da forma }\end{array}$} & $\begin{array}{c}\text { Interpretação } \\
\text { defınida }\end{array}$ & 39 & 51,3 & 31 & 40,8 & 6 & 7,9 & $\begin{array}{c}76 \\
(63,9 \%)\end{array}$ \\
\hline & $\begin{array}{l}\text { Interpretação } \\
\text { indefinida }\end{array}$ & 14 & 32,6 & 21 & 48,8 & 8 & 18,6 & $\begin{array}{c}43 \\
(36,1 \%)\end{array}$ \\
\hline \multirow{3}{*}{$\begin{array}{l}\text { Tipo de frase } \\
\text { em que a } \\
\text { forma ocorre }\end{array}$} & Afirmativa & 36 & 44,4 & 34 & 42 & 11 & 13,6 & $\begin{array}{c}81 \\
(68,1 \%)\end{array}$ \\
\hline & Negativa & 7 & 43,8 & 7 & 43,8 & 2 & 12,5 & $\begin{array}{c}16 \\
(13,4 \%)\end{array}$ \\
\hline & Interrogativa & 10 & 45,5 & 11 & 50 & 1 & 4,5 & $\begin{array}{c}22 \\
(18,5 \%)\end{array}$ \\
\hline \multirow{2}{*}{ Sexo/gênero } & Feminino & 26 & 49,1 & 18 & 34 & 9 & 17 & $\begin{array}{c}53 \\
(44,5 \%)\end{array}$ \\
\hline & Masculino & 27 & 40,9 & 34 & 51,5 & 5 & 7,6 & $\begin{array}{c}66 \\
(55,5 \%)\end{array}$ \\
\hline TOTAL & & 53 & 44,5 & 52 & 43,7 & 14 & 11,8 & 119 \\
\hline
\end{tabular}

Fonte: Elaboração própria.

A primeira conclusão a que se chega, ao observarmos a Tabela acima, é de que a segunda pessoa não é influenciada pela língua ancestral, já que as formas são características do português brasileiro. Os resultados indicam que, na linguagem dos informantes, aparecem as formas você, cê e ocê. Num total de 119 dados, você e cê têm quase a mesma percentagem: $44,5 \%$ de você e $43,7 \%$ de cê. A diferença entre o número de ocorrências de você e de cê, pelos nossos informantes bilíngues, é mínima: 0,8\%, o que diferencia São Bento de outras comunidades rurais e urbanas, até de Vitória, a cidade mais próxima.

Outra marca da linguagem dos informantes é o uso de ocê, que teve 14 ocorrências $\left(11,8 \%\right.$ do total). 0 uso de ocê e o léxico dos uranienses ${ }^{11}$ demonstram que o português

11 Exemplos de vocábulos usados pelos informantes são: vinhero/vieram, joeiado/ajoelhado, parma/palma, provilho/polvilho, dizi/diz, cabemo/acabamos, sabo/sábado etc. Futuramente nos ocuparemos desse estudo. 
falado em São Bento de Urânia é tipicamente rural, com características semelhantes às apresentadas por Bortoni-Ricardo (2011), quanto ao português de uma cidade satélite de Brasília.

No que respeita à função sintática que as três formas desempenham, estas foram usadas, em sua maioria, na função de sujeito (93,3\% do total). Nessa função, cê foi a variante mais utilizada - 46,8\%, contra 41,4\% de você. Por sua vez, nas demais funções, a variante cê não ocorre e ocê aparece uma única vez nos dados.

Com relação à variável social sexo/gênero, os resultados indicam que os homens preferem as formas cê e você, nessa ordem, ao passo que as mulheres preferem você e cê. É interessante notar que os dois informantes homens saíam mais da comunidade do que elas, para vender seus produtos em Vitória, e, portanto, tinham mais contato com as pessoas da capital, mas, como veremos, em Vitória a variante favorecida é você, muito acima de cê. Por sua vez, a informante JG, que mais frequentou a escola, foi quem falou mais você. Assim, pensamos que a preferência de JG pelo uso de você pode dever-se à maior escolarização dessa informante, haja vista que cê e ocê, por serem variantes inovadoras, poderiam ter sido consideradas erradas e seu uso ter sido sistematicamente corrigido pela escola. ${ }^{12}$

Exemplos encontrados no corpus são:

SL:

(1) Seu pai falou: "Oh, você não vai", e não vai mesmo não. Não ia não.

(2) A Itália é tudo antiga, tudo que ocê quer ver antigo cê acha lá.

RB:

(1) Porque eu me chamo como você, brasileiro, que eu sou aqui do Brasil.

(2) Vítor Hugo, cê sabe que é Vítor Hugo ${ }^{13}$ ?

(3) E oferecia para tudo quanto: "Ocês quer tomar uma também?"

12 No Espírito Santo, desconhecemos qualquer comunidade cujos membros utilizem o pronome tu. Portanto, você é a forma não marcada do português falado em todo o estado.

13 Vítor Hugo é o nome de uma localidade próxima a São Bento de Urânia. 
CDB:

(1) É, você não conhece não.

(2) E hoje em dia cê tem que comprar farinha. Mais ninguém tem.

(3) Era caroço de milho, se ocê não sabia fazer o dever [de casa].

JG:

'Você quer a vida da sua mãe ou você quer doar sangue?'

(10) 'Comigo não, cê não vai namorar mais não' - falei.

(11) Desiste. Se ocê quer, talvez ocês vão salvar.

A fim de estabelecermos uma comparação de São Bento com outras localidades, apresentamos o quadro a seguir. Pelo fato de seus moradores nos informarem que tropeiros e meeiros procedentes de Minas Gerais passavam por ela e ali residiam, inclusive as professoras da escola local, os resultados de localidades mineiras são apresentados.

Quadro 1. Resultados gerais para você, ocê, cê em São Bento de Urânia, ES e em outras localidades

\begin{tabular}{|c|c|c|c|c|c|c|c|}
\hline \multirow{2}{*}{ LOCALIDADES } & \multicolumn{2}{|c|}{ VOCÊ } & \multicolumn{2}{|c|}{ CÊ } & \multicolumn{2}{|c|}{ OCÊ } & \multirow{2}{*}{ TOTAL } \\
\hline & $\mathbf{N}$ & $\%$ & $\mathbf{N}$ & $\%$ & $\mathbf{N}$ & $\%$ & \\
\hline São Bento de Urânia & 53 & 44,5 & 52 & 43,7 & 14 & 11,8 & 119 \\
\hline Vitória (CALMON, 2010, p. 80) & 1477 & 74,9 & 477 & 24,2 & 17 & 0,9 & 1971 \\
\hline $\begin{array}{c}\text { Arcos, MG (GONÇALVES, 2008, } \\
\text { p. 192) }\end{array}$ & 113 & 22 & 277 & 54 & 120 & 24 & 510 \\
\hline $\begin{array}{c}\text { São Francisco (COELHO, 1999, } \\
\text { p. 54) }\end{array}$ & 125 & 20 & 355 & 56 & 142 & 23 & 629 \\
\hline $\begin{array}{c}\text { Território Gurutubano, MG } \\
(\mathrm{COELHO}, 2010, \text { p. 281) }\end{array}$ & 13 & 6,6 & 161 & 82,2 & 22 & 11,2 & 196 \\
\hline $\begin{array}{c}\text { Belo Horizonte } \\
\text { (RAMOS, 1997, p. 46-48) }\end{array}$ & 112 & 33 & 189 & 55 & 41 & 12 & 342 \\
\hline $\begin{array}{l}\text { Belo Horizonte - amostra } 2002 \\
\text { (PERES, 2006, p. 117) }\end{array}$ & 342 & 23,5 & 1055 & 72,6 & 56 & 3,9 & 1453 \\
\hline
\end{tabular}

Fonte: Elaboração própria.

14 Foram registradas ainda sete ocorrências da variante 'ancê', que corresponde a $1 \%$ do total de 629 dados. 
Vemos que os nossos resultados gerais não se alinham com os das outras localidades apresentadas; pelo contrário, são muito diferentes, especialmente com respeito à distribuição das variantes você e cê. A diferença de 0,8\% entre as duas está muito distante das demais comunidades. Quanto à variante ocê, os resultados de São Bento se aproximam de Gurutuba e de Belo Horizonte, na amostra de Ramos (1997).

Dessa forma, vemos que a segunda pessoa em São Bento de Urânia tem um uso peculiar, que - acreditamos - não se deve ao bilinguismo dos informantes, mas sim às especificidades da colonização da comunidade e do contato que se deu entre os primeiros moradores e os falantes de português. Em suma, nossos dados confirmam que os aspectos extralinguísticos importam muito para as consequências linguísticas do contato entre línguas.

A fim de que pudéssemos conhecer qual(is) a(s) variável(is) favorecedora(s) da utilização da forma você, primeiramente a forma ocê - que teve o menor número de ocorrências - foi retirada e, em seguida, os knockouts foram eliminados, para que pudéssemos utilizar o Programa Goldvarb X. Entre todas as variáveis analisadas, apenas o contexto de interpretação da forma foi selecionado. Os resultados aparecem no Quadro 2, a seguir.

Quadro 2. Variável selecionada pelo Programa Goldvarb X quanto à variante você

\begin{tabular}{|c|c|c|}
\hline \multicolumn{2}{|c|}{ VARIÁVEL SELECIONADA } & Peso Relativo \\
\hline \multirow{2}{*}{$\begin{array}{c}\text { Contexto de interpretação } \\
\text { da forma }\end{array}$} & $\begin{array}{c}\text { Interpretação } \\
\text { definida }\end{array}$ & 0.58 \\
\cline { 2 - 3 } & $\begin{array}{c}\text { Interpretação } \\
\text { indefinida }\end{array}$ & 0.35 \\
\hline
\end{tabular}

Log likelihood $=-62.777$

Significância $=0.046$

Fonte: Elaboração própria.

A seleção de apenas uma variável evidencia a forte coesão linguística dos informantes mais idosos da comunidade. Por sua vez, os resultados obtidos para a expressão da referência vão de encontro à maioria das demais localidades apresentadas neste trabalho.

Em Vitória (CALMON, 2010), a variável contexto de interpretação da forma não foi selecionada pelo Programa Goldvarb X como favorecedora do uso da variante você, mas a autora nos apresenta seus resultados: a referência indefinida $(74,7 \%)$ é ligeiramente superior à referência definida (72,6\%). Em São Francisco-MG (COELHO, 1999, p. 63), 
você aparece em contextos de referência indefinida $22 \%$ das vezes e, em contextos de referência definida, 19\%. Em Arcos, MG (GONÇALVES, 2008, p. 185), você aparece como referência indefinida $44 \%$ e definida, $14 \%$.

Com relação a Belo Horizonte, os dados de Peres (2006, p. 131) indicam que você é mais preferentemente usado como referência indefinida $(P R=.63)$ do que como referência definida (PR = .36). Já os dados de Ramos $(1997$, p. 50) apontam que você é mais usado como referência definida $(37 \%)$ do que como indefinida $(28 \%)$, resultados que se assemelham aos de São Bento de Urânia. Esses resultados indicam que os usos linguísticos têm estreita relação com os processos históricos e sociais de formação e estruturação de cada comunidade.

\section{Considerações finais}

A expressão da segunda pessoa pelos bilíngues desta pesquisa se caracteriza por diferir tanto das zonas rurais vistas - onde não houve imigração - quanto de Vitória, a capital do Espírito Santo. Por outro lado, em outros níveis, como o léxico, essa variedade contém muitos traços do português rural (BORTONI-RICARDO, 2011).

Os resultados encontrados mostram a unidade linguística da comunidade de São Bento de Urânia. Segundo os nossos informantes, na pequena comunidade, todos são parentes ou pelo menos compadres e comadres, ou seja, a rede fechada garante a coesão de sua linguagem. Os uranienses não vão muito a Vitória. Eles resolvem suas demandas na Sede de Marechal Floriano, um município vizinho colonizado por alemães e também por italianos. Visitas a Vitória só mesmo para consultas a médicos mais especializados ou em casos especiais.

Entretanto, um estudo posterior precisa ser feito em São Bento de Urânia, abarcando principalmente os adolescentes e jovens - que já não são mais bilíngues e que saem da comunidade para estudar -, a fim de sabermos se está havendo mudança com relação à expressão da segunda pessoa.

Além disso, outras comunidades colonizadas por imigrantes merecem a nossa atenção, para conhecermos como se deram os contatos entre as línguas de imigração e o português, no Espírito Santo. Como dissemos, esses estudos são importantes para, entre outros objetivos, pensarmos em melhores estratégias de ensino da língua portuguesa, nessas localidades. 


\section{REFERÊNCIAS}

ALI, S. Gramática histórica da língua portuguesa. 5. ed. São Paulo: Melhoramentos, 1965.

APPEL, R.; MUYSKEN, P. Bilingüismo y contacto de lenguas. Tradução Anxo M. Lorenzo Suárez y Clara I. Bouzada Fernández. Barcelona: Ariel, 1996.

BAKER, C.; JONES, S. P. Encyclopedia of bilingualism and bilingual education. Clevedon: Multilingual Matters, 1998.

BIGAZZI, A. R. C. Italianos: história e memória de uma comunidade. São Paulo: Cia. Editora Nacional, 2006. (Série Lazuli - Imigrantes no Brasil)

BREMENKAMP, E. S. Análise sociolinguística da manutenção da língua pomerana em Santa Maria Jetibá, Espírito Santo. 2014. Dissertação (Mestrado em Linguística) - Universidade Federal do Espírito Santo, Vitória, 2014.

BORTONI-RICARDO, S.-M. Do campo para a cidade: estudo sociolinguístico de migração e redes sociais. São Paulo: Parábola, 2011.

CALMON, E. N. Ponte da passagem: você e cê transitando na fala de Vitória (ES). 2010. Dissertação (Mestrado em Linguística) - Universidade Federal do Espírito Santo, Vitória, 2010.

CÂMARA Jr., J. M. História e estrutura da língua portuguesa. 2. ed. Rio de Janeiro: Padrão, 1976.

CINTRA, L. L. Sobre Formas de Tratamento na língua portuguesa: ensaios. Lisboa: Horizonte, 1972.

COELHO, M. do S. V. Uma abordagem variacionista do uso da forma você no norte de Minas. 1999. Dissertação (Mestrado em Letras: Linguística) - Faculdade de Letras, Universidade Federal de Minas Gerais. 1999.

COELHO, M. do S. V. Os gurutubanos; língua, história e cultura. 2010. Tese (Doutorado em Linguística e Língua Portuguesa) - Pontifícia Universidade Católica de Minas Gerais, 2010. 
COELHO, M. do S. V. De Vossa Mercê a cê no português brasileiro: da gramática ao discurso. Revista Vertentes, São João del Rei, v. 32, p. 221-230, 2008. Disponível em: www. ufsj.edu.br/vertentes/edicoes.php\#. Acesso em: 02 jan. 2009.

COMINOTTI, K. S. S. O contato linguístico entre o vêneto e o português em São Bento de Urânia, Alfredo Chaves, ES: uma análise sócio-histórica. 2015. Dissertação (Mestrado em Linguística) - Universidade Federal do Espírito Santo, Vitória, 2015.

CONDE, B. S. Senhores de fé e de escravos: a escravidão nas fazendas jesuíticas do Espírito Santo. In: Anais do $4^{\circ}$ Encontro Escravidão e Liberdade no Brasil Meridional. Curitiba: UFPR, p. 01-10, 13-15 maio, 2009. Disponível em: http://bit.ly/2Jvdguw. Acesso em: 03 mar. 2014.

COOK, M. Uma teoria de interpretação das formas de tratamento na língua portuguesa. Hispania, n. 80, p. 451-464, set. 1997.

COULMAS, F. Sociolinguistics: the study of speakers' choices. Cambridge: Cambridge Press, 2005.

COUTINHO, I. de L. Pontos de gramática histórica. 7. ed. rev. Rio de Janeiro: Ao Livro Técnico, 1976.

COUTO, H. H. do. Linguística, ecologia e ecolinguística: contato de línguas. São Paulo: Contexto, 2009.

DADALTO, M. C. Cenas de violência na tessitura entre imigrantes italianos e brasileiros no interior do Espírito Santo. Boletim do museu paraense Emílio Goeldi, Ciências Humanas, v. 12, p. 189-200, 2017.

DERENZI, L. S. Os italianos no Espírito Santo. Rio de Janeiro: Artenova, 1974.

DUARTE, M. E. L. Do pronome nulo ao pronome pleno: a trajetória do sujeito no português do Brasil. In: ROBERTS, I.; KATO, M. A. Português brasileiro: uma viagem diacrônica. 2. ed. Campinas: Ed. da UNICAMP, 1996.

FARACO, C. A. O tratamento você em português; uma abordagem histórica. Fragmenta, Curitiba: Ed. da UFPR, n. 13, p. 51-82, 1996.

FRANCESCHETTO, C. Imigrantes do Espírito Santo. Vitória (ES): Arquivo púbico do Estado do Espírito Santo, 2014. (Canaã, v. 19). 
FRANZINA, E. A grande emigração: o êxodo dos italianos do Vêneto para o Brasil. Tradução Edilene Toledo e Luigi Biondi. Campinas: Editora da UNICAMP, 2006.

GONÇALVES, C. R. Uma abordagem sociolinguística do uso das formas você, ocê e cê no português. 2008. Tese (Doutorado em Linguística) - Faculdade de Filosofia, Letras e Ciências Humanas, Universidade de São Paulo, 2008.

KLIPPEL-MACHADO, R. Práticas de oralidade e de escrita nas aulas de português em contexto de diversidade linguística: o contato entre as línguas portuguesa e hunsrückisch em Marechal Floriano, ES. 2018. Dissertação (Mestrado Profissional em Letras) Universidade Federal do Rio Grande do Norte, Natal; Instituto Federal do Espírito Santo, Vitória, 2018.

LABOV, W. Sociolinguistic patterns. Philadelphia: University of Pennsylvania Press, 1972.

LABOV, W. Principles of Linguistic Change: social factors. Oxford: Blackwell, 2001.

LOPES, C. R. dos S. O quadro dos pronomes pessoais. Rio de Janeiro: manuscrito. 2003a.

LOPES, C. R. dos S. Vossa Mercê > você e Vuestra Merced > Usted: o percurso evolutivo ibérico. Linguística, ALFAL, v. 14, p. 173-190, 2003b.

LOPES, C. R. dos S.; OLIVEIRA, T. L.; CARVALHO, B. B. A. de. A expressão da $2^{a}$ pessoa do singular: variação e percepção numa abordagem experimental. Todas as Letras, São Paulo, v. 18, n. 2, p. 117-132, 2016.

LUZ, M. dos S. Fórmulas de tratamento do português. Revista Portuguesa de Filologia, Coimbra, v. II, T. I-II, p. 256-363, 1956.

MARTINUZZO, J. A. Germânicos nas terras do Espírito Santo. Tradução Helmar Reinhard Rölke. Vitória: Governo do Estado do Espírito Santo, 2009. Edição bilíngue Português e Alemão. Disponível em: http://bit.ly/2Sc/Kt7. Acesso em: 24 ago. 2018.

MATRAS, Y. Language contact. Cambridge: Cambridge University Press, 2009.

MENÓN, O. P. O sistema pronominal do português do Brasil. Letras, Curitiba: Ed. da UFPR, n. 44, p. 91-106, 1995. 
MENÓN, O. P. Pronome de segunda pessoa no sul do Brasil: tu/você/o senhor em Vinhas da Ira. Letras de Hoje, Porto Alegre, v. 35, n. 1, p. 121-164, mar. 2000.

MOREIRA, T. H.; PERRONE, A. História e geografia do Espírito Santo. 8. ed. Vitória: [s.n.], 2007.

MYERS-SCOTTON, C. Multiple voices: an introduction to bilingualism. Oxford: Blackwell Publishing, 2006.

MONTRUL, S. El bilinguismo en el mundo hispanohablante. West-Sussex, UK: WileyBlackwell, 2013.

NASCENTES, A. O tratamento de "você" no Brasil. Letras, Curitiba/PR: Ed. UFPR, v. 6, n. 5, p. 114-122, 1956.

OLIVEIRA, J. T. História do estado do Espírito Santo. 3. ed. Vitória: Arquivo Público do Estado do Espírito Santo, 2008. Coleção Canaã, volume 08. Disponível em: www.ape.es.gov.br. Acesso em: 05 mar. 2014.

OLIVEIRA, M.; RAMOS, J. O estatuto de 'você' no preenchimento do sujeito. Comunicação apresentada no Encontro da Alfal, Costa Rica, 2002.

PEREIRA, E. C. Grammatica histórica. 9. ed. São Paulo: Nacional, 1935. (contém Prólogo datado de 1915). Disponível em: http://bit.ly/2G9lHcG. Acesso em: 23 dez. 2014.

PERES, E. P. O uso de você, ocê e cê em Belo Horizonte: um estudo em tempo aparente e em tempo real. 2006. Tese (Doutorado em Letras/Linguística) - Faculdade de Letras, Universidade Federal de Minas Gerais, 2006.

PERES, E. P. Aspectos sócio-históricos do contato entre o dialeto vêneto e o português no Espírito Santo. Revista (Con)textos Linguísticos, Vitória, v. 8, n. 10.1, 2014. Disponível em: http://www.periodicos.ufes.br/contextoslinguisticos. Acesso em: 02 mar. 2015.

PERES, E. P.; DADALTO, M. C.; BOTTER, B. A imigração italiana e os contatos linguísticos no Espírito Santo. In: FROSI, V. M.; MISTURINI, B. Imigração italiana: estudos e pesquisas. São Leopoldo: Oikos, 2016. 
PETERLE, B. D. Análise sociolinguística da realização do ditongo nasal tônico <ão> em São Bento de Urânia, Alfredo Chaves/ES: o papel da variável sexo/gênero. 2017. Dissertação (Mestrado em Estudos Linguísticos) - Universidade Federal do Espírito Santo, Vitória, 2017.

RAMOS, J. O uso das formas você, ocê e cê no dialeto mineiro. In: DA HORA, D. (org.). Diversidade linguística no Brasil. João Pessoa, PB: Idéia, 1997. p. 43-60.

RAMOS, J.; OLIVEIRA, M. Pronomes de segunda pessoa: uma abordagem diacrônica. Comunicação apresentada na Reunião da ANPOLL, Gramado, RS, 2002.

SALETTO, N. Donatários, colonos, índios e jesuítas: o início da colonização do Espírito Santo. Vitória: Arquivo Público do Estado do Espírito Santo, 2011. Coleção Canaã, volume 13. Disponível em: www.ape.es.gov.br. Acesso em: 04 mar. 2014.

SANKOFF, D.; TAGLIAMONTE, S.; SMITH, E. Goldvarb $X$ - A multivariate analysis application. Toronto: Department of Linguistics; Ottawa: Department of Mathematics, 2005. Disponível em: http://bit.ly/2NYmzaO. Acesso em: 04 mar. 2014.

SCHERRE, M. M. P. Variação dos pronomes tu e você. In: MARTINS, M. A.; ABRAÇADO, J. (org.). Mapeamento sociolinguístico do português brasileiro. São Paulo: Contexto, 2015.

VILAÇA, A. Receita para um romanceiro; São Bento de Urânia. Vitória: SEBRAE, 2010.

VITRAL, L. A forma CÊ e a noção de gramaticalização. Revista de Estudos da Linguagem, Belo Horizonte, v. 4, n. 1, p. 115-124, jan./jun. 1996.

WEINREICH, U. Language in contact: findings and problems. Paris: The Hague Mouton, 1970 [1953]. 